\title{
RETORNO DE NUTRIENTES VIA DEPOSIÇÃO DE SERAPILHEIRA EM UM POVOAMENTO DE ACÁCIA-NEGRA (Acacia mearnsii De Wild.) NO ESTADO DO RIO GRANDE DO SUL ${ }^{1}$
}

\begin{abstract}
Mauro Valdir Schumacher ${ }^{2}$, Eleandro José Brun ${ }^{3}$, Loiva Maria Rodrigues ${ }^{4}$ e Elias Moreira dos Santos ${ }^{5}$
RESUMO - Com este estudo, objetivou-se avaliar os aspectos envolvidos na transferência de serapilheira e nutrientes ao solo em um povoamento de acácia-negra (Acacia mearnsii De Wild.) com 3 anos de idade, em Butiá-RS. Para tanto, foram alocadas, sistematicamente, cinco parcelas de $18 \times 24 \mathrm{~m}$, onde foram distribuídos 20 coletores de serapilheira de $1 \mathrm{~m}^{2}$ (quatro em cada). Para coleta de galhos, foram demarcadas na superfície do solo 15 subparcelas de 3 × 3 m. O material interceptado foi coletado mensalmente entre maio/1999 e dezembro/2001. Após a coleta, o material foi separado em frações (folhas, galhos, flores, frutos e fezes), seco em estufa, pesado, moído e analisado quanto aos teores de N, P, K, Ca e Mg. A deposição média anual de serapilheira alcançou 5,85 Mg/ha, sendo composta por $77 \%$ de folhas, $3,7 \%$ de galhos, $2,5 \%$ de flores, $2,4 \%$ de frutos e $14,3 \%$ de fezes de lagarta. A baixa deposição de galhos foi atribuída à pequena intensidade do processo de desrama natural da espécie, principalmente nessa idade do povoamento. A deposição de serapilheira foi mais concentrada no verão. O maior fornecimento de nutrientes ao solo ocorreu através da fração folhas. As frações com maiores teores de $\mathrm{N}, \mathrm{P}$ e $\mathrm{Mg}$ foram flores e frutos, somente perdendo para as folhas e fezes quanto à concentração de $\mathrm{Ca}$ e não diferindo em relação ao $\mathrm{K}$. A magnitude de transferência de nutrientes ao solo, em kg/ha, foi igual a 106,2 de $\mathrm{N}>62,8$ de $\mathrm{Ca}>41,8$ de $\mathrm{K}>$ 9,4 de $\mathrm{Mg}>3,4$ de $\mathrm{P}$.
\end{abstract}

Palavras-chave: Sustentabilidade, nutrição florestal e reflorestamento.

\section{NUTRIENT RETURN VIA LITTER DEPOSITION IN A BLACK WATTLE (Acacia mearnsii De Wild.) STAND IN RIO GRANDE DO SUL, BRAZIL}

\begin{abstract}
This study aimed to evaluate all the aspects involved in the transfer of litterfall and nutrients into the soil in a 3-year-old Black-wattle stand (Acacia mearnsii De Wild.), in Butiá, RS. For the experiment, 5 plots of $18 \mathrm{~m} \times 24 \mathrm{~m}$ were allocated systematically. In these plots, 20 litter collectors of $1 \mathrm{~m}^{2}$ were distributed (4 in each plot). For branch collection, 15 splitplots of $3 \mathrm{~m} \times 3 \mathrm{~m}$ were delimited on the soil surface. The intercepted material was collected monthly from May/1999 to December/2001. After collection, the material was separated in fractions (leaves, branches, flowers, fruits and feces), oven-dried, weighed, ground and chemically analyzed for concentrations of $\mathrm{N}, \mathrm{P}, \mathrm{K}, \mathrm{Ca}$ and $\mathrm{Mg}$. The annual average deposition of litter achieved $5.85 \mathrm{Mg} / \mathrm{ha}$, being $77.0 \%$ leaves, $3.7 \%$ branches, $2.5 \%$ flowers, $2.4 \%$ fruits and $14.3 \%$ feces. The low deposition of branches. Litterfall was more concentrated in the summer. The largest supply of nutrients to the soil occurred through the fraction leaves. The fractions with higher concentrations of $N, P$ and $\mathrm{Mg}$ were the flowers and the fruits, only differing from the leaves and feces in Ca concentration and not differing in relation to $K$. The magnitude of nutrient transfer to the soil was 106.2 of $N>62.8$ of $\mathrm{Ca}>41.8$ of $\mathrm{K}>9.4$ of $\mathrm{Mg}>3.4$ of $\mathrm{P}$, in $\mathrm{kg} / \mathrm{ha}$.
\end{abstract}

Key words: $\quad$ Sustainability, forest nutrition, and reforestation.

1 Recebido para publicação em 4.11.2002.

Aceito para publicação em 4.11.2003.

2 Eng. Florestal, Prof. Dr. nat techn do Departamento de Ciências Florestais/CCR/UFSM, 97105-900 Santa Maria-RS, <schuma@ccr.ufsm.br>, Fone: (0xx55)220-8444 - R. 36. Bolsista do CNPq; ${ }^{3}$ Eng. Florestal, Mestrando do Programa de PósGraduação em Engenharia Florestal da UFSM. Santa Maria-RS, <eleandrojbrun@mail.ufsm.br>; ${ }^{4}$ Acadêmica do Curso de Graduação em Engenharia Florestal/CCR/UFSM. ${ }^{5}$ Eng. Florestal - Empresa Agroseta, Estância Velha-RS. 


\section{INTRODUÇÃO}

A acácia-negra (Acacia mearnsii De Wild.), planta pertencente à família Leguminosae, é originária da Austrália sul-oriental, sendo árvore de grande importância econômica e ornamental. Os objetivos econômicos são a produção de casca, para as indústrias de tanino, e ultimamente, em função da exportação como matéria-prima para a indústria de celulose, a produção de madeira.

A maior importância da acácia-negra está na sua capacidade de fixação do nitrogênio atmosférico $\left(\mathrm{N}_{2}\right)$ e de incorporação da matéria orgânica ao solo, fornecendo proteção e proporcionando a manutenção produtiva deste. Segundo Auer \& Silva (1992), essa espécie pode fixar cerca de $200 \mathrm{~kg} / \mathrm{ha} / \mathrm{ano}$ de nitrogênio em regiões tropicais.

O estudo do ciclo de nutrientes nessas florestas é de importância fundamental, possibilitando a previsão de situações que poderiam ser críticas a médio e longo prazo, tanto em relação à produtividade, como em relação às características do solo. A contínua exportação de nutrientes através da colheita reduz a capacidade produtiva do sítio e pode desestabilizar o ecossistema, comprometendo a produtividade dos futuros ciclos (Pereira et al., 1984; Reis \& Barros, 1990).

A permanência da serapilheira na floresta fará com que essa seja reaproveitada no ciclo de nutrientes do ecossistema, através de sua decomposição e da liberação dos minerais constituintes para uma posterior reabsorção pelas raízes das plantas. A importância desse ciclo que se forma entre a comunidade viva e o seu meio é evidenciada nas florestas que se mantêm em áreas com solos de baixa fertilidade.

A serapilheira é fundamental para a sustentabilidade da produção florestal com acácia-negra, pois permite que, pelo menos em parte, ocorra o retorno ao solo de uma significativa quantidade de nutrientes absorvidos pelas plantas. Tal fato contará positivamente no balanço de nutrientes no sítio, diminuindo os impactos que a colheita poderá causar.

Carpanezzi (1997), analisando diversos trabalhos realizados em plantações de espécies de rápido crescimento ou em talhões de regeneração natural dominados por uma só espécie, reconheceu um padrão comum de produção de serapilheira em relação à idade. Inicialmente, o valor da deposição cresce com a idade, até atingir um limite, variando a velocidade de aumento da deposição, a idade e o valor máximo de acordo com cada caso.
Depois de atingido o limite, o valor da deposição estabiliza-se ou cai lenta (para espécies longevas) e rapidamente (para espécies de vida curta).

Os padrões de produção de serapilheira também variam de uma espécie para outra. Schumacher (1992), estudando aspectos da ciclagem de nutrientes em talhões plantados com diferentes espécies de eucalipto, observou uma deposição anual de serapilheira, em Mg/ha/ano, igual a 7,2, 3,1 e 5,8 para Eucalyptus camaldulensis Dehnh., Eucalyptus grandis W. Hill ex Maiden e Eucalyptus torelliana F. Muell., respectivamente.

Objetivou-se com o presente trabalho estimar a quantidade de serapilheira produzida, nas suas diferentes frações; avaliar a sazonalidade anual de deposição; e quantificar os nutrientes devolvidos ao solo da floresta, via serapilheira, em um povoamento de acácia-negra com 3 anos de idade.

\section{MATERIAL E MÉTODOS}

\subsection{Caracterização da Área de Estudo}

Este estudo foi realizado em um povoamento de acácia-negra com 3 anos de idade, localizado no município de Butiá-RS, situado próximo às coordenadas geográficas de $30^{\circ} 07^{\prime} 12^{\prime \prime}$ de latitude sul e $51^{\circ} 57^{\prime} 45^{\prime \prime}$ de longitude oeste, a uma altitude média de $35 \mathrm{~m}$.

Segundo a classificação de Köppen, o clima é do tipo Cfa, caracterizado como subtropical úmido. A temperatura média anual é de $18^{\circ} \mathrm{C}$, com a média das mínimas oscilando entre -3 e $18{ }^{\circ} \mathrm{C}$ e a média das máximas ultrapassando os $23^{\circ} \mathrm{C}$. A precipitação pluviométrica anual é em torno de $1.600 \mathrm{~mm}$ e a insolação é de 2.300 horas (Moreno, 1961).

O solo da região em estudo pertence à Unidade de Mapeamento São Jerônimo, classificado como Argissolo Vermelho distrófico típico, textura argilosa, relevo ondulado e substrato granito. Normalmente, esses solos são fortemente ácidos, com soma de bases e teores de matéria orgânica baixos (Streck et al., 2002).

O preparo do solo foi apenas uma gradagem na linha de plantio. Para o controle da vegetação espontânea, fezse a aplicação de herbicida na faixa gradeada $(70 \mathrm{~cm}) . \mathrm{O}$ plantio das sementes foi realizado através de plantadeira hidráulica PHA. As sementes foram distribuídas em espaçamento de 1,33 x 3,0 m. Após 12 meses realizouse o raleio, deixando a planta de maior vigor. O controle de formigas foi realizado periodicamente. 


\subsection{Metodologia}

Em área com condições homogêneas de sítio de uma floresta de acácia-negra com 3 anos de idade, foram alocadas, pelo método de amostragem sistemática (Péllico Neto \& Brena, 1997), cinco parcelas de 18 x 24 m cada. Nestas parcelas, foram distribuídos 20 coletores de serapilheira com $1 \mathrm{~m}^{2}$ de área útil, constituídos de madeira e fundo em tela de náilon de $1 \mathrm{~mm}$, tendo sido instalados a 0,80 m de altura do solo (Figura 1). Os quatro coletores de cada parcela foram distribuídos dois na linha e dois na entrelinha de plantio. Para coleta de galhos, foram demarcadas 15 subparcelas de 3 x 3 m na superfície do solo.

O material interceptado nos coletores e nas parcelas de coleta de galhos foi recolhido mensalmente, no período de maio de 1999 até dezembro de 2001.

Na coleta, o material foi acondicionado em embalagem de papel, identificado e levado para o Laboratório de Ecologia Florestal da Universidade Federal de Santa Maria (UFSM), onde foi separado nas frações folhas, galhos, flores, frutos e fezes de lagartas. Após a separação, o material foi seco em estufa de circulação e renovação de ar a $75^{\circ} \mathrm{C}$, por 72 horas, sendo posteriormente pesado em balança de precisão $(0,01 \mathrm{~g})$. De cada fração coletada mensalmente foram retiradas alíquotas homogêneas de material, que foram trituradas em moinho Wiley com peneira de 30 mesh e posteriormente analisadas quanto aos teores de N, P, K, Ca e Mg, de acordo com a metodologia de Tedesco et al. (1995).

De posse dos dados a respeito da produção de serapilheira e do seu respectivo conteúdo de nutrientes, eles foram analisados no software SPSS 7.5 for Windows.

\section{RESULTADOS E DISCUSSÃO}

\subsection{Produção de Serapilheira}

Quantidades significativas de nutrientes podem retornar ao solo através da queda dos componentes senescentes da parte aérea das plantas e sua posterior decomposição. Estes fragmentos orgânicos, ao caírem sobre o solo, formam uma camada de serapilheira, que compreende folhas, caules, frutos, flores, bem como restos de animais e material fecal (Golley, 1978).

A exemplo disto, a serapilheira amostrada neste estudo considerou também as fezes da lagarta-desfolhadora Adeloneivaia subangulata, que desenvolve um hábito de herbivoria intenso, consumindo os folíolos das plantas de acácia-negra. Em seguida, o restante da folha (ráquis) seca cai, aumentando o peso de serapilheira produzida, principalmente no verão.

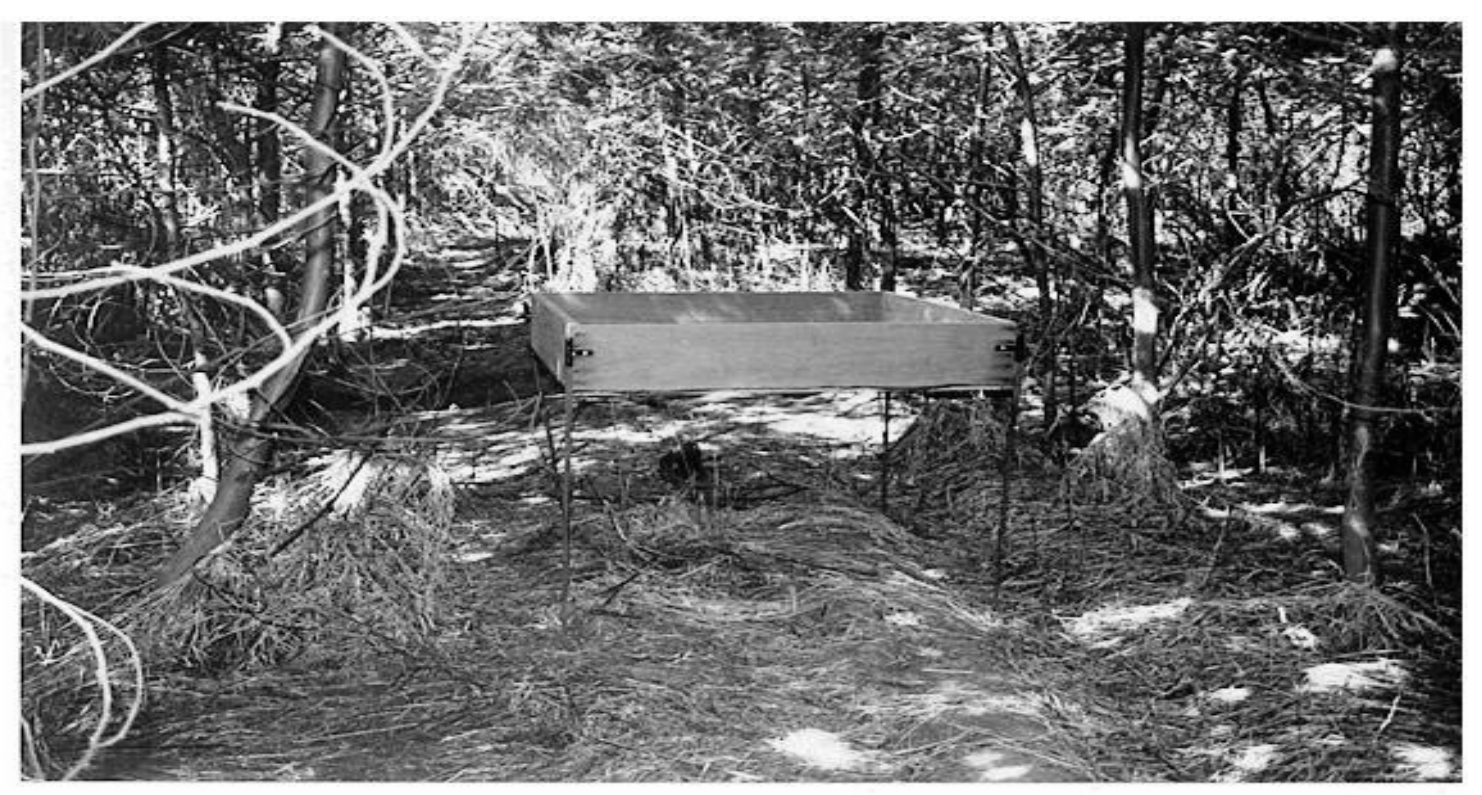

Figura 1 - Aspecto do col etor de serapilheira no experimento em povoamento de acácia-negra. Butiá-RS.

Figure 1 - Litter collector in the Acacia-negra stand. Butia, RS. 
A quantidade de serapilheira depositada no solo durante o período total de estudo foi calculada para uma deposição média anual (Quadro 1).

Quadro 1 - Deposição média mensal e anual de serapilheira (kg/ha) para o período de maio/1999 a dezembro/2001, no povoamento de acácia-negra. Butiá-RS

Table 1 - Monthly and annual average litter deposition ( $\mathrm{kg} / \mathrm{ha}$ ) from May/1999 to December/2001, in the Blackwattle stand. Butiá-RS

\begin{tabular}{|l|r|r|r|r|r|r|}
\hline \multirow{2}{*}{ Mês } & \multicolumn{7}{|c|}{ Fração (kg/ha) } \\
\cline { 2 - 7 } & Folhas & Galhos & Flores & Frutos & Fezes & Serapilheira \\
\hline Janeiro & 514 & 4 & 0 & 0 & 224 & 742 \\
\hline Fevereiro & 280 & 0 & 0 & 5 & 365 & 650 \\
\hline Marco & 168 & 0 & 0 & 10 & 190 & 368 \\
\hline Abril & 505 & 9 & 16 & 10 & 26 & 566 \\
\hline Maio & 754 & 21 & 0 & 24 & 6 & 805 \\
\hline Junho & 317 & 7 & 2 & 13 & 0 & 339 \\
\hline Julho & 258 & 6 & 1 & 8 & 0 & 273 \\
\hline Agosto & 282 & 13 & 14 & 8 & 0 & 317 \\
\hline Setembro & 327 & 25 & 20 & 8 & 0 & 380 \\
\hline Outubro & 298 & 44 & 84 & 12 & 0 & 438 \\
\hline Novembro & 339 & 51 & 8 & 30 & 26 & 454 \\
\hline Dezembro & 462 & 37 & 4 & 15 & 0 & 518 \\
\hline Total & 4.504 & 217 & 149 & 143 & 837 & 5.850 \\
\hline \% & 77,0 & 3,7 & 2,5 & 2,4 & 14,3 & 100,0 \\
\hline
\end{tabular}

A deposição média anual de serapilheira alcançou $5,85 \mathrm{Mg} / \mathrm{ha}$, sendo formada em sua maioria por folhas (77\%), o que comprova a grande importância desta fração para a serapilheira. Esta produção foi inferior à encontrada para povoamentos de Mimosa caesalpiniifolia, Acacia mangium e Acacia holosericea no Rio de Janeiro, por Andrade (1997), que foi de 10,16, 9,13 e $9,06 \mathrm{Mg} / \mathrm{ha}$, respectivamente.

Proctor (1983), em estudos realizados em diferentes florestas do mundo iden1 tificou uma grande quantidade (média de 70\%) de folhas na serapilheira.

A deposição da fração galhos alcançou porcentuais relativamente pequenos, em comparação com estudos de povoamentos de outras espécies. Não puderam ser observadas quedas significativas desta fração, fato justificado por se tratar de um povoamento jovem, onde ainda não se iniciou de forma intensa um processo de desrama natural, o que é também típico da espécie, ou seja, a manutenção de boa parte dos galhos senescentes presos ao tronco. Andrade (1997) relatou porcentuais de galhos na serapilheira depositados em torno de 5, 6 e 17\% para Acacia mangium, Acacia holosericea e Mimosa caesalpiniifolia, respectivamente. Estes fatos são exclusivamente característicos da espécie, quando se fala de povoamentos não-manejados com desbastes ou desramas.

As frações de material reprodutivo (flores e frutos) alcançaram porcentuais de deposição em trono de 2,5\%, bem inferiores ao do estudo de Andrade (1997), que apresentou 23, 29 e 14\%, respectivamente, na ordem anteriormente apresentada. Tal resultado pode estar relacionado ao fato de as espécies pesquisadas pelo autor, apesar de terem sido estudadas em idade semelhante à deste estudo, estarem implantadas em solo com elevado grau de degradação, com baixa fertilidade e densidade alta, o que faz com que as plantas, como estratégia de sobrevivência, produzam maior quantidade de material reprodutivo.

A quantificação da deposição de fezes de lagartas não foi previamente programada, no entanto esta passou a compor importante fração da serapilheira, que começou a ser quantificada a partir de janeiro de 2000. A maior deposição de fezes ocorreu no verão, no período de maior consumo de folhagem pelas lagartas, notadamente em fevereiro, em que foi de mais de $360 \mathrm{~kg} / \mathrm{ha}$, diminuindo em maio e inexistindo a partir de junho, devido à aplicação de inseticida biológico. A contribuição desta fração para devolução de serapilheira foi, em média, de 14,3\%.

A produção de serapilheira foi estudada em quatro povoamentos florestais puros e em um povoamento misto, implantados em área experimental de cerrado, no interior do Estado de São Paulo, e avaliados por Garrido \& Poggiani (1982). De acordo com os autores, a maior deposição ocorreu para o povoamento de cambará (Gochnatia polimorpha Less.), sendo igual a $4.751 \mathrm{~kg} / \mathrm{ha}$, seguido pelo angico (Anadenanthera falcata (Benth) Brenan), com $4.381 \mathrm{~kg} / \mathrm{ha}$; pelo povoamento misto, com $2.616 \mathrm{~kg} / \mathrm{ha}$; pela aroeira (Astronium urundeuva (Allemão) Engl.), com $2.297 \mathrm{~kg} / \mathrm{ha}$; e pelo ipê-roxo (Tabebuia impetiginosa (Mart.) Standl.), com 980 kg/ha.

A deposição de serapilheira em talhões experimentais de Mimosa scabrella e Eucalyptus viminalis, localizados em região de mineração no Paraná, foi estudada por Chiaranda et al. (1983), a qual atingiu, para as duas espécies, 6,30 e 3,00 Mg/ha, respectivamente. $\mathrm{O}$ padrão de deposição foi semelhante para as duas espécies, 
com uma queda de folhas mais acentuada no período do verão.

Poggiani et al. (1987) estudaram a deposição de serapilheira em talhões experimentais de Pinus taeda, Eucalyptus viminalis e Mimosa scabrella, plantados em área degradada pela extração de xisto betuminoso no Paraná, onde a produção alcançou 4.391, 2791 e $4.790 \mathrm{~kg} / \mathrm{ha}$, respectivamente.

Extrai-se da literatura que boa parte dos estudos quanto à produção de serapilheira demonstra que espécies leguminosas apresentam superioridade neste aspecto. A maior produção das espécies leguminosas é devido à sua característica de crescimento rápido e maior eficiência de utilização dos nutrientes extraídos do solo, em comparação com as outras espécies.

A variação sazonal média na deposição de serapilheira, além da fração folhas e galhos, durante os três anos de estudo, é apresentada na Figura 2.

A deposição de serapilheira em povoamentos da espécie aumenta no período da primavera e do verão, começando a subir a partir de outubro, chegando até fevereiro, quando a produção cai novamente. Desta forma, boas correlações foram encontradas entre a produção de serapilheira e a temperatura média mensal $(\mathrm{r}=0,42)$. Não se verificou efeito significativo da precipitação na produção de serapilheira $(r=0,04)$, o que leva a crer que o comando que desencadeia a produção de serapilheira para a espécie é sim o calor, de forma que a maior atividade fisiológica dos indivíduos neste período faz também com que ocorra uma intensa troca da folhagem, quando o material senescente é liberado, dando lugar a uma folhagem nova e fotossinteticamente mais ativa.

O pico ocorrido no mês de maio reflete uma condição meteorológica adversa, ocorrida na forma de fortes ventos em maio de 2001, o que ocasionou a queda de grande quantidade de folhas e material lenhoso.

A queda de flores teve seu maior pico em outubro, apresentando contribuições pequenas nos meses de abril, agosto e setembro, entre outros meses. Normalmente a acácia tem o início de sua floração em setembro, mas devido à influência de fatores climáticos adversos pode ocorrer floração fora da época normal, como o ocorrido no mês de abril.

Os frutos apresentaram contribuições relativamente contínuas durante o ano, com alguma elevação nos meses de maio e novembro, o que demonstra uma característica

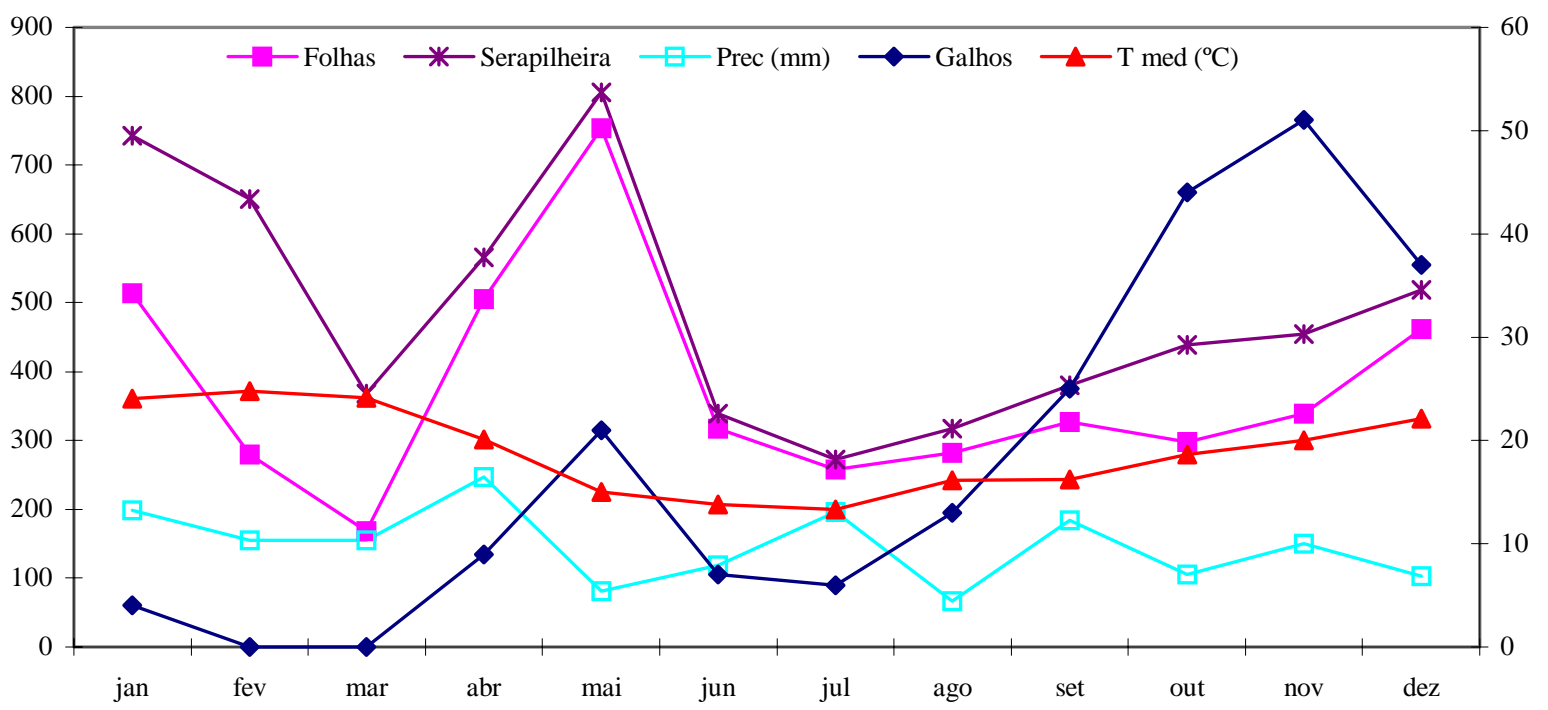

Figura 2 - Variação mensal média na deposição de serapilheira (kg/ha), comparada com a preci pitação (mm) e temperatura média mensal (ํ) , no povoamento de acácia-negra. Butiá-RS (a variação na deposição da fração gal hos e a temperatura são acompanhadas no eixo secundário do gráfico).

Figure 2 - Average monthly variation in litter deposition ( $\mathrm{kg} / \mathrm{ha}$ ) as compared with rainfall (mm) and average monthly temperature $\left({ }^{\circ} \mathrm{C}\right.$ ) in the Black-wattlestand. Butiá, RS (variation in the deposition of thefraction branches and temperature are monitored in the secondary axis of the graph). 
da espécie quanto à persistência de certa porcentagem dos frutos na copa por período considerável, caindo estes em função de ventos, como ocorrido em maio de 2001, desconsiderando nesta observação o mês de novembro como sendo mês normal de deposição de frutos, após a diminuição da floração.

\subsection{Transferência de Nutrientes ao Solo Via Serapilheira}

Os dados referentes à concentração média de nutrientes nas frações de serapilheira estão no Quadro 2. Os dados apresentaram distribuição normal, portanto não sofrendo nenhuma espécie de transformação.

A quantidade total de nutrientes minerais em uma floresta é determinada pela sua quantidade na vegetação (folhas, ramos, cascas, lenho, raízes etc.), na serapilheira e no solo.

Segundo Pritchett (1979), a absorção dos nutrientes pelas árvores é influenciada pela espécie, pela cobertura florestal e pelas condições de solo e clima. Em princípio, a absorção anual de nutrientes pela maioria das espécies florestais é da mesma ordem da apresentada pelas culturas agrícolas, mas como a maior parte dos nutrientes absorvidos é devolvida para o piso florestal, quantidades relativamente pequenas são retidas no acréscimo anual da biomassa arbórea.

As diferentes frações formadoras da serapilheira apresentaram composições químicas distintas. O teor de $\mathrm{N}$ foi mais elevado nos frutos, cuja concentração não diferiu em relação à das frações folhas, flores e fezes. A menor concentração de $\mathrm{N}$ ocorreu nos galhos. O P esteve mais concentrado nas flores, cuja concentração não diferiu das encontradas nas folhas, nos frutos e nas fezes. Os galhos, novamente, mostraram a menor concentração. A concentração de potássio não diferiu estatisticamente entre as frações.

Quanto ao Ca, a fração fezes de lagarta apresentou a maior concentração, como já era esperado, em virtude da origem da fração. A concentração deste elemento na fração folhas não diferiu da encontrada nas fezes. As demais frações apresentaram concentrações inferiores deste elemento. O magnésio esteve mais concentrado nos frutos, apresentando teores menores para as demais frações.

Se a fração flores e frutos for considerada como material reprodutivo, o que acontece em muitas pesquisas com devolução de nutrientes via serapilheira, pode-se perceber que esta fração é a mais rica em N, P, K e Mg, somente perdendo lugar para as folhas e fezes quanto à concentração de cálcio.

A elevada concentração de fósforo nas flores e nos frutos é explicada por este elemento ter a função de estimular o crescimento, apressar a maturação e ajudar a formação das sementes, a respiração e a absorção iônica de outros elementos (Ferri, 1985). O potássio é um elemento altamente móvel no floema e prontamente redistribuído para os órgãos novos em crescimento, sendo uma de suas funções proteger a planta contra doenças, além de auxiliar na manutenção dos frutos na planta, o que ocasiona a maior concentração nesta fração, apesar da pouca diferença em relação às demais.

A fração fezes apresentou altas concentrações de $\mathrm{Ca}$ e também foi uma das mais ricas em $\mathrm{P}$ e $\mathrm{K}$, porém apresentando teores intermediários de $\mathrm{N}$ e inferiores de $\mathrm{Mg}$.

Quadro 2 - Concentração média de nutrientes (g/kg) nas frações de serapilheira do povoamento de acácia-negra. Butiá-RS (os valores entre parênteses referem-se ao erro padrão da média)

Table 2 - Average concentration of nutrients $(\mathrm{g} / \mathrm{kg})$ in the litter fractions of the Black-wattle stand. Butiá, RS (The values between parentheses refer to the average standard error)

\begin{tabular}{|c|c|c|c|c|c|}
\hline \multirow{2}{*}{ Fração } & \multicolumn{5}{|c|}{ Nutriente $(\mathrm{g} / \mathrm{kg})$} \\
\cline { 2 - 6 } & $\mathrm{N}$ & $\mathrm{P}$ & $\mathrm{K}$ & $\mathrm{Ca}$ & $\mathrm{Mg}$ \\
\hline Folhas & $18,57 \mathrm{ab} *( \pm 4,17)$ & $0,57 \mathrm{ab}( \pm 0,30)$ & $6,80 \mathrm{a}( \pm 3,50)$ & $10,57 \mathrm{ab}( \pm 4,68)$ & $1,58 \mathrm{~b}( \pm 0,29)$ \\
\hline Galhos & $14,88 \mathrm{~b}( \pm 4,22)$ & $0,41 \mathrm{~b}( \pm 0,23)$ & $5,98 \mathrm{a}( \pm 3,70)$ & $6,04 \mathrm{~b}( \pm 2,91)$ & $1,70 \mathrm{~b}( \pm 0,28)$ \\
\hline Flores & $19,37 \mathrm{ab}( \pm 4,42)$ & $0,80 \mathrm{a}( \pm 0,43)$ & $7,09 \mathrm{a}( \pm 4,98)$ & $6,38 \mathrm{~b}( \pm 3,65)$ & $1,77 \mathrm{~b}( \pm 0,34)$ \\
\hline Frutos & $20,41 \mathrm{a}( \pm 3,59)$ & $0,76 \mathrm{ab}( \pm 0,37)$ & $9,00 \mathrm{a}( \pm 2,72)$ & $8,13 \mathrm{~b}( \pm 4,23)$ & $2,26 \mathrm{a}( \pm 0,57)$ \\
\hline Fezes & $16,30 \mathrm{ab}( \pm 7,40)$ & $0,59 \mathrm{ab}( \pm 0,37)$ & $8,91 \mathrm{a}( \pm 1,69)$ & $14,03 \mathrm{a}( \pm 5,53)$ & $1,56 \mathrm{~b}( \pm 0,25)$ \\
\hline Média & 17,91 & 0,63 & 7,56 & 9,03 & 1,77 \\
\hline
\end{tabular}

* Médias seguidas pela mesma letra, na vertical, não diferem entre si pelo teste de Tukey, a 5\% de probabilidade de erro. 
Quadro 3 - Transferência média anual de $\mathrm{N}, \mathrm{P}, \mathrm{K}, \mathrm{Ca}$ e $\mathrm{Mg}$ pelas diferentes frações formadoras da serapilheira $(\mathrm{Q}=$ quantidade em $\mathrm{kg} / \mathrm{ha})$ e a contribuição porcentual (\%) de cada fração para o total do elemento

Table $3-N, P, K, C a$ and $M g$ average annual transfer by the different litter fractions $(Q=q u a n t i t y$ in $\mathrm{kg} / \mathrm{ha})$ and contribution (\%) of each fraction for the total of the element

\begin{tabular}{|c|c|c|c|c|c|c|c|c|c|c|c|}
\hline \multirow{2}{*}{ Fração } & \multirow{2}{*}{$\begin{array}{c}\text { Peso } \\
(\mathrm{kg} / \mathrm{ha})\end{array}$} & \multicolumn{2}{|c|}{$\mathrm{N}$} & \multicolumn{2}{|c|}{$\mathrm{P}$} & \multicolumn{2}{|c|}{$\mathrm{K}$} & \multicolumn{2}{|c|}{$\mathrm{Ca}$} & \multicolumn{2}{|c|}{$\mathrm{Mg}$} \\
\hline & & Q & $\%$ & $\mathrm{Q}$ & $\%$ & Q & $\%$ & $\mathrm{Q}$ & $\%$ & $\mathrm{Q}$ & $\%$ \\
\hline 1 & 4.504 & 83,6 & 78,7 & 2,6 & 76,5 & 30,6 & 73,2 & 47,6 & 75,8 & 7,1 & 75,5 \\
\hline 2 & 217 & 3,2 & 3,1 & 0,1 & 2,9 & 1,3 & 3,1 & 1,3 & 2,1 & 0,4 & 4,3 \\
\hline 3 & 149 & 2,9 & 2,7 & 0,1 & 2,9 & 1,1 & 2,7 & 1,0 & 1,6 & 0,3 & 3,2 \\
\hline 4 & 143 & 2,9 & 2,7 & 0,1 & 2,9 & 1,3 & 3,1 & 1,2 & 1,9 & 0,3 & 3,2 \\
\hline 5 & 837 & 13,6 & 12,8 & 0,5 & 14,8 & 7,5 & 17,9 & 11,7 & 18,6 & 1,3 & 13,8 \\
\hline 6 & 5.850 & 106,2 & 100,0 & 3,4 & 100,0 & 41,8 & 100,0 & 62,8 & 100,0 & 9,4 & 100,0 \\
\hline
\end{tabular}

1: folhas, 2: galhos, 3: flores, 4: frutos, 5: fezes e 6: total.

No Quadro 3 é apresentada a transferência média anual de nutrientes ao solo via serapilheira. A maior contribuição para a ciclagem de nutrientes é oferecida pela fração folhas, em virtude de sua predominante biomassa. Sua participação relativa variou de $73,2 \%$ para o potássio até $78,7 \%$ para o nitrogênio.

A fração galhos foi responsável por contribuições porcentuais, em nutrientes, menores do que para a massa seca de serapilheira. Somente para o Mg a fração galhos contribuiu com um porcentual maior do que para massa de serapilheira $(4,3 \%)$.

As frações flores e frutos, apesar das significativas concentrações de elementos na massa seca, apresentam baixa contribuição em nutrientes retornados ao solo, em virtude de sua pequena biomassa.

$\mathrm{O}$ nitrogênio foi o nutriente fornecido em maior quantidade ao solo da floresta, fato esperado em virtude de a espécie ser uma importante fixadora do $\mathrm{N}$ atmosférico. O cálcio apresentou uma baixa devolução relativa, uma vez que estudos realizados com povoamentos de diversas espécies demonstram que o elemento apresenta devoluções semelhantes ao N, algumas vezes o excedendo. Neste sentido, a magnitude de transferência de nutrientes ao solo do povoamento foi: $\mathrm{N}>\mathrm{Ca}>\mathrm{K}>\mathrm{Mg}$ $>\mathrm{P}$, demonstrando o grande potencial que a espécie apresenta para a fixação biológica do elemento.

\section{CONCLUSÕES}

A deposição média anual de serapilheira encontrada neste estudo $(5,85 \mathrm{Mg} / \mathrm{ha})$ demonstra a importância desta via de ciclagem de nutrientes para manutenção da produtividade do sítio. A quantidade de serapilheira depositada foi crescente, desde a implantação do experimento, aos 3 anos de idade da floresta, até o fim da avaliação.

A fração folhas apresenta-se como predominante na serapilheira devolvida ao solo (77\%). A baixa contribuição da fração galhos $(3,7 \%)$ na idade avaliada é atribuída à pequena intensidade do processo de desrama natural, que tende a aumentar em idades posteriores. As frações flores $(2,5 \%)$ e frutos $(2,4 \%)$ apresentam sazonalidade de deposição definida de acordo com as características fenológicas da espécie.

A deposição de serapilheira apresentou-se sazonal, com picos durante o verão e menores produções no inverno. A deposição mais intensa é concomitante com o período de maior atividade fisiológica (verão), ocorrendo a troca da folhagem senescente.

$\mathrm{O} \mathrm{N}$ e o $\mathrm{P}$ apresentaram-se com teores superiores nas folhas, nas flores, nos frutos e nas fezes. O Ca apresentou-se mais concentrado nas folhas e fezes. $\mathrm{O} \mathrm{Mg}$ esteve mais concentrado nos frutos. Os teores do K não diferiram entre as diferentes frações.

A transferência anual de nitrogênio ao solo esteve acima de $106 \mathrm{~kg} / \mathrm{ha}$. O segundo nutriente mais devolvido ao solo foi o cálcio, com mais de $62 \mathrm{~kg} / \mathrm{ha}$. Os demais nutrientes apresentaram a seguinte magnitude de devolução: $\mathrm{K}>\mathrm{Mg}>\mathrm{P}$.

O fornecimento de nutrientes ao solo ocorre fundamentalmente através da fração folhas (acima de 70\%).

R. Árvore, Viçosa-MG, v.27, n.6, p.791-798, 2003 
Apesar de esta fração não apresentar as maiores concentrações de nutrientes, é a que mais contribui para o processo de ciclagem de nutrientes, pela sua grande massa produzida e depositada no solo.

\section{REFERÊNCIAS BIBLIOGRÁFICAS}

ANDRADE, A. G. Ciclagem de nutrientes e arquitetura radicular de leguminosas arbóreas de interesse para revegetação de solos degradados e estabilização de encostas. 1997. $166 \mathrm{f}$. Tese (Doutorado em Agronomia) Universidade Federal Rural do Rio de Janeiro, Rio de Janeiro, 1997.

AUER, C. G.; SILVA, R. Fixação de nitrogênio em espécies arbóreas. In: CARDOSO, E. J. B. N.; TSI, M.; NEVES, M. C. P. Microbiologia do solo. Campinas: Universidade Estadual de São Paulo, 1992. p. 160-167.

CARPANEZZI, A. A. Banco de sementes e deposição de folhedo e seus nutrientes em povoamentos de Bracatinga (Mimosa scabrella Bentham) na região metropolitana de Curitiba-PR. 1997. 177 f. Tese (Doutorado em Biologia Vegetal) - Universidade Estadual Paulista, Rio Claro, 1997.

CHIARANDA, J. R.; POGGIANI, F.; SIMÕES, J. W. Crescimento das árvores e deposição de folhedo em talhões florestais plantados em solos alterados pela mineração do xisto. IPEF, v. 25, p. 25-28, 1983.

FERRI, M. G. Fisiologia vegetal 1. 2.ed. São Paulo: EPU, 1985. $362 \mathrm{p}$.

GARRIDO, M. A. O.; POGGIANI, F. Avaliação da quantidade e do conteúdo de nutrientes no folhedo de alguns povoamentos puros e mistos de espécies indígenas. Silvicultura em São Paulo, v. 15/16, p. 1-22, 1982.

GOLLEY, F. B. et al. Ciclagem de minerais em um ecossistema de Floresta Tropical Úmida. Tradução Eurípedes Malavolta. São Paulo: USP, 1978. 256 p.

MORENO, J. A. Clima do Rio Grande do Sul. Porto Alegre: Secretaria da Agricultura, 1961. 73 p.
PELLICO NETO, S.; BRENA, D. A. Inventário Florestal. Curitiba: UFPR. 1997.

PEREIRA, A. R. et al. Concentração e distribuição de nutrientes em Eucalyptus grandis em função da idade, cultivado na região do cerrado. Brasil Florestal. Brasília: 1984.

POGGIANI, F. et al. Quantificação da deposição de folhedo em talhões experimentais de Pinus taeda, Eucalyptus viminalis e Mimosa scabrella plantados em uma área degradada pela mineração do xisto betuminoso. IPEF, v. 47 , p. $21-29,1987$

PRITCHETT, W. L. Properties and management of forest soils. New York: J. Wiley, 1979. 500 p.

PROCTOR, J. Tropical forest litterfall. I. Problems of data comparison. In: SUTTON, S. L.; WHITMORE, T. C.; CHADWICK, A. C. (Eds). Tropical rain forest: Ecology and management. III. Decomposition and nutrient cycling. London: Special publications series of Britsh Ecological Society, 1983. p. 267-273.

REIS, M. G. F.; BARROS, N. F. Ciclagem de nutrientes em plantios de eucalipto. In: BARROS, N. F.; NOVAIS R. F. (Eds). Relação solo eucalipto. Viçosa: Editora Folha de Viçosa, 1990. p. 265-301.

SCHUMACHER, M. V. Aspectos da ciclagem de nutrientes e do microclima em talhões de Eucalyptus camaldulensis Dehnh., Eucalyptus grandis W. Hill ex Maiden e Eucalyptus torelliana F. Muell. 1992. 87 f. Dissertação (Mestrado em Engenharia Florestal) - Escola Superior de Agricultura "Luiz de Queiroz", Piracicaba, 1992.

STRECK, E. V. et al. Solos do Rio Grande do Sul. Porto Alegre: Emater-RS/UFRGS, 2002. 107 p.

TEDESCO, M. J. et al. Análise de solo, plantas e outros materiais. Porto Alegre: UFRGS, 1995. 118 p. (Boletim Técnico $\mathrm{n}^{\circ}$ 5). 